\title{
Analysis of an Intelligent Graphical Tutoring System Using the Internet of Things (IoT) to Develop the Competency of Embedded Systems
}

\author{
https://doi.org/10.3991/ijoe.v15i04.9511 \\ Jiragorn Chalermdit ( $\left.{ }^{\varpi}\right)$, Prachyanun Nilsook, Panita Wannapiroon \\ King Mongkut's University of Technology, Bangkok, Thailand \\ c_jiragorn@hotmail.com
}

\begin{abstract}
The objectives of this research are to analyse and assess an intelligent graphical tutoring system using the internet of things (IoT) to develop the efficiency of embedded systems. The research findings suggest that an intelligent system is composed of six modules: 1) student, 2) graphical tutoring, 3) expert, 4) knowledge, 5) evaluation and 6) user interface. The result of a composition assessment performed by experts indicates that the overall results are at a high level. The system suitability scored the highest level which can be applied to real life situations.
\end{abstract}

Keywords-Intelligent tutoring systems, internet of things (IoT), graphical programming, embedded system, embedded system competency.

\section{Introduction}

The rapid development of information and communication technology (ICT) means that it is increasingly used in education to create innovative teaching materials and enable learners to acquire knowledge. The $21^{\text {st }}$ century is an era of fast-paced technological development that requires different outcomes from students and affects the learning process [1] Technological change and innovation in the delivery of education provides students with easier access to information sources. As technology advances, it is used for building systems that facilitate students' learning and promote higher educational standards as well as improving the quality of students learning due to the ability embedded in the systems. Currently, this field of study focuses on embedded system programming and the internet of things (IoT) which are important for national development. This technology is also applied to the measurement of sportrelated injuries [2] the monitoring of patients [3] as well as education [4]. After completing their studies, undergraduate students can apply their knowledge to innovative creation and standard testing of embedded system efficiency. Sharing news and information has gradually become easier, and knowledge exchange engages many audiences on websites [5] which means that it is possible to develop knowledge and skills in this way. Therefore, a learning management system is an essential component as students are already system users. It must be designed to attract and motivate students 
to engage in the learning process [6]. The quality of student learning must be prioritized and facilities and learning methods provided that encourage students to become independent learners. Students should be able to set their own goals and improve their academic ability. A positive attitude should be fostered while developing students' behaviour towards computers [7]. These innovative learning processes will be effective after students have engaged in the learning activities.

An intelligent tutoring system (ITS) is an innovative learning platform that supports learning activities within classrooms and distance education via the internet. ITSs aim to provide learning support and customized instruction to help students personalize their learning [8]. This is a new way to supplement the best learning by using a computer database and teaching strategies that enable an authentic learning environment and suit the individual needs of students [9]. Additionally, activities should be provided during lessons to engage students and to develop their knowledge and skills [10].

One advantage of ITSs is the ability to generate knowledge and derive new knowledge in response to learner's questions according to their intelligence levels. The system assesses whether students lack a body of knowledge and identifies areas where their learning needs improvement. It does this by using visual block-based programming focused on the problem-solving process. The graphical programming method is described as a series of functions where the composition of a photo, colour or symbol is programmed instead of line of code which is more effective and efficient [11]. A program is integrated with the intelligent tutoring system to help students get a better understanding of microcontroller programming principles relating to the development of embedded systems.

Embedded systems are widely used in several sectors including industry, agriculture, transportation, safety and education. Today, educational institutions focus on embedded system learning to develop students' abilities and so they can create new technology or produce innovative ideas [12]. This is useful for problem solving or designing a wireless sensor network (WSN), which is an innovative technology using a prediction-based approach that transfers data through the embedded system [13]. WSNs are also used to transfer and store data in cloud computing via devices with the IoT [14]. Accordingly, the learning development of embedded system technology in educational institutions is associated with supporting and promoting research activities, developing embedded system technology as well as maximizing the potential of students and personnel.

Therefore, the researchers are interested in the analysis of graphical intelligent tutoring systems using IoT to develop and embed system efficiency and in employing the system as a tool to help develop knowledge and skills and provide intelligent and productive classroom activities. In addition, these systems provide a great opportunity to conduct independent research and review the success of the development of students' skills and technical knowledge in relation to embedded system efficiency. 


\section{$2 \quad$ Literature Reviews}

\subsection{Intelligent tutoring system}

The intelligent tutoring system (ITS) is an innovative learning platform that uses electronic media to support students learning and provide course content, tests, exercises and learning activities. The system holds a body of knowledge and delivers effective presentations of lessons. It follows a thorough process in accordance with learning principles and aims to provide customized instructions that suit the individual needs and intelligence levels of students [15]. The ITS is an expert knowledge model with the capacity to make logical decisions [16]. It uses teaching methods such as preplanning teaching or advanced topics teaching [17] and is as responsive to a student's needs as a human tutor would be. Not only does the system engage students in practice and collaborative learning but it also creates a conducive learning atmosphere [18] in a flexible and adaptive way that is suitable for individuals' needs [19]. Additionally, ITS provides immediate feedback for learners to personalize and optimize learning ability and make the teaching process easier [20]. It can be used both within the classroom and for distance education via the internet [21]. When developing ITSs a broad knowledge of the study area must be considered including topic and course content as well as an understanding of the students' knowledge base, ability and behaviour. The strategic skills of teachers relating to the presentation process and their lesson plans, methods and tests must also be applied to the expert knowledge-based system. The principles of the system are to provide questions for learners using an incremental mechanical method that rewards students for any correct responses to questions. Where students' answers are different to the correct response, the system will carry out a further assessment [22] to try to improve student learning outcomes. During the assessment process, the system also organizes a learning plan, future lessons and formalizes the learning. Then, the system generates new questions that are in keeping with student's learning management skills [23]. Teachers are not required to outline a plan since the system is able to provide timely feedback for the learners through the tutoring model and knowledge-based system [24]. This research can be applied to the field of education to produce intelligent tutoring systems as part of the technological revolution taking place in education [25]. It can also apply to the development of students' analytical skills and their understanding of the concept of independent learning which will help them to acquire knowledge and use technology to create future innovations.

\subsection{Graphical programming}

Graphical programming is defined as a graphical approach to programming using diagrams and symbols instead of lines of code or a series of functions. It allows users to interact with a program and see the immediate results. It uses simple methods and features in a positive developmental setting and is divided into two parts: Open source platforms and proprietary platforms [26]. This allows developers to create a program without writing a single line of code and fix programming errors to improve the pro- 
gram. However, beginners can find it difficult and tire of learning [27] so online graphic programming is developed by replacing text with block diagrams or symbols as well as converting commands back into a programming language.

During this research, a graphic programming tool is used to assist teaching in collaboration with an intelligent tutoring system to support learners according to their needs when creating programs connected to embedded systems [28]. This is suitable for beginners because the programming process includes the execution of a command block to create a script, which is a bit like a Lego programming block that cannot be redistributed without prior written permission from its author and to avoid data entry mistakes in its programming. According to the process, it makes a programming language easier for beginners to learn and design projects with creativity and imagination. Whereas course content involves graphical programming by employing a range of tools. These can include a microcontroller, sensor and other electronic devices such as motion controls, sensors, result displays and electric ray robot sound programming [29] using a miniblog, and an open source graphic program for Arduino, Multiplo, physical computing etc. [30].

\subsection{Internet of Things}

The Internet of Things (IoT) environment supports device-to-device communication and protocol with LAN and wireless connectivity. The IoT consists of a personal recognition system and is the basic ability of machines to recognize things, people, and movements in response to requests, collaboration and data exchange. Its ability can lead to innovation success in the industrial, agricultural, logistics [31], communication, safety [32] and education sectors. Such innovative products can improve the learning environment, encourage learners and increase efficiency in learning [33]. Furthermore, the IoT can be applied in daily life in items such as motion sensors, home security systems that detect movement, sending signals as a request for an auto on/off switch, medical monitors for patients and elders as well as medical data transmission.

Smart kitchen appliances such as sensor knives work using the IoT that monitors movement and uses sensing principles to detect the blade during cutting and chopping; it works like robotic hands and helps prevent user errors. Load cells are attached to smart chopping boards designed for fruit or meat. For safety reasons, when items are placed on the smart chopping board, the blade motion is detected by an acceleration sensor [34]. Data for processing is transmitted through an internet data centre server [35]. Crucial aspects of the IoT include:

- Content-Data transmission at any time

- Computing-Processing data at anytime and anywhere and on any device

- Collection-Providing a wide variety of services

- Connectivity-Can connect with all hosts and networks

- Communication-From anywhere in the world

- Convergence-Data transmission on different platforms [35]. 
Data transmission using the IoT is successful if the connected items, communications and backbone work seamlessly with the top layers. Therefore, the IoT must have the following aspects:

- Identification-Personal recognition system

- Sensing-The process of data collection by detecting a multitude of real-world attributes, such as humidity, temperature, light intensity, smoke and much more

- Communication-Connectivity enabling a sensor to transmit a signal for processing functions within internal or external servers or internet networks

- Computation-A processing system with the apparatus for distributed computing on the sensor data as well as for transmitting analytical data to users or any device

- Service-In terms of providing information technology services, data-driven decision making and response management systems for adding sensor devices and processing systems within IoT systems as well as the monitoring, maintenance and determination processes

- Semantics-The searching and downloading process as shown in Fig 1 [36]

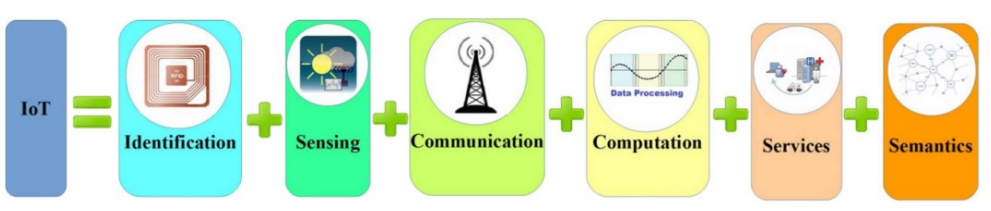

Fig. 1. Composition of the Internet of Things (IoT) [36]

Based on the previous information, the IoT technology has multiple benefits which can be applied in many ways. The IoT technology is part of this research initiative to support intelligent tutoring systems that can encourage and increase learners' essential skills and give them a competitive edge. It seems obvious that the role of technology in education is vital to create a learning society and this could apply to many sectors.

\subsection{Embedded system competency}

An embedded system is an electronic system within the central processing unit (CPU) and is used in household appliances and consumer electronics including mobile phones, digital cameras, washing machines, air conditioners and electronic systems for automotive control etc. Today, embedded systems are commonly found in devices and are constantly increasing. They are also used in several sectors including education, agriculture, industry, medicine, security as well as in electrical and electronic appliances and robot technology [37]. With significant growth in and minimal re-design of such devices, embedded systems can be integrated into sensors [38] which are easy to use due to their small physical size. Memory units in microcontrollers can be used for multiple purposes and meet many individual needs while increasing the capacity for such devices through software. 
Embedded systems are continually growing, so they have become an important aspect of research as well as being an integral part of students' courses where they are tested for efficiency and used for self-assessment of knowledge.

\section{Methodology}

Phase 1-A synthesis of graphical intelligent tutoring systems using the IoT for developing the efficiency of embedded systems, as follows:

- A study of relevant research papers about intelligent tutoring systems to discover any synthesis in the composition of graphical intelligent tutoring systems [10], [39], [40], [41], [42], [43], [44].

- A study of relevant research papers and literature reviews relating to graphical programming for programming [27], [45], [30].

- A study of relevant research papers and literature reviews relating to the internet of things, [31], [32], [33], [34], [35], [36], supporting students learning with course content [46], [37], [38] as well as the development and assessment of embedded system efficiency.

- A synthesis of graphical intelligent tutoring systems using the internet of things for developing the efficiency of embedded systems.

Phase 2-Suitability assessment methods of graphic intelligent tutoring system composition using the internet of things for developing the efficiency of embedded systems as follows:

- Creating a suitability assessment tool for graphic intelligent tutoring system composition using the internet of things for developing the efficiency of embedded systems.

- Assessment of graphical intelligent tutoring system composition using the internet of things to develop the efficiency of embedded systems performed by ten experts with doctoral degrees and at least ten years teaching experience in higher education. Five experts have a comprehensive knowledge of teaching design and five have a comprehensive knowledge of technology.

- Analysis of suitability assessment results regarding graphical intelligent tutoring system composition using the internet of things for developing the efficiency of embedded systems using mean $(\bar{x})$ and standard deviation (SD).

\section{$4 \quad$ Result}

The analytical approach of intelligent graphical tutoring system composition using the internet of things to develop the efficiency of embedded systems with concepts and related theories is described in the following research [6], [10], [23], [47], [48], [49], [50] and summarized in Table 1. 
Table 1. Analysis of the composition of intelligent tutoring systems.

\begin{tabular}{|c|c|c|c|c|c|c|c|c|c|}
\hline $\begin{array}{l}\text { Intelligent } \\
\text { Tutoring } \\
\text { System }\end{array}$ & $\begin{array}{c}\text { Zhihong } \\
\text { Liu, } \\
\text { Libing, } \\
\text { Zequing } \\
\text { [43] }\end{array}$ & \begin{tabular}{|c|} 
Jugo, \\
Kovačić \& \\
Slavuj \\
{$[44]$}
\end{tabular} & $\begin{array}{l}\text { Naghiza- } \\
\text { deh } \\
\& \\
\text { Moradi [3] }\end{array}$ & $\begin{array}{l}\text { Ramesh } \\
\text { Rao \& } \\
\text { Rama- } \\
\text { nathan } \\
{[7]}\end{array}$ & \begin{tabular}{|l|} 
Si \\
Allal \\
Zarouk \\
$\&$ \\
Khaldi \\
{$[47]$}
\end{tabular} & $\begin{array}{l}\text { Thai } \\
\text { Nghe \& } \\
\text { Schmidt } \\
\text { Thieme[ } \\
\text { 48] }\end{array}$ & $\begin{array}{l}\text { Vinchur- } \\
\text { kar } \\
\& \text { } \\
\text { Sasiku- } \\
\text { mar[49] }\end{array}$ & \begin{tabular}{|l|} 
Jimenez, \\
Juarez, \\
Ramirez \\
, Navar- \\
ro, \\
Coronel \\
and \\
Cas- \\
tillo[21]
\end{tabular} & $\begin{array}{l}\text { Ramirez- } \\
\text { NoriegaJua- } \\
\text { rez, Ra- } \\
\text { merez, }\end{array}$ \\
\hline \begin{tabular}{|l|} 
Domain \\
Module \\
\end{tabular} & $\checkmark$ & & $\checkmark$ & & $\checkmark$ & $\checkmark$ & $\checkmark$ & $\checkmark$ & $\checkmark$ \\
\hline \begin{tabular}{|l} 
Tutoring \\
Module
\end{tabular} & $\checkmark$ & $\checkmark$ & $\checkmark$ & $\checkmark$ & $\checkmark$ & $\checkmark$ & $\checkmark$ & $\checkmark$ & $\checkmark$ \\
\hline \begin{tabular}{|l|}
$\begin{array}{l}\text { Student } \\
\text { Module }\end{array}$ \\
\end{tabular} & $\checkmark$ & $\checkmark$ & $\checkmark$ & $\checkmark$ & $\checkmark$ & $\checkmark$ & & $\checkmark$ & $\checkmark$ \\
\hline \begin{tabular}{|l|} 
Expert \\
Module
\end{tabular} & $\checkmark$ & $\checkmark$ & & $\checkmark$ & $\checkmark$ & & & & \\
\hline $\begin{array}{l}\text { User Inter- } \\
\text { face }\end{array}$ & $\checkmark$ & $\checkmark$ & $\checkmark$ & $\checkmark$ & $\checkmark$ & $\checkmark$ & $\checkmark$ & $\checkmark$ & $\checkmark$ \\
\hline \begin{tabular}{|l|} 
Knowledge \\
Module \\
\end{tabular} & & & & & & & $\checkmark$ & & \\
\hline \begin{tabular}{|l|} 
Evaluation \\
Module \\
\end{tabular} & & & & & & & & & $\checkmark$ \\
\hline
\end{tabular}

According to the analysis of documents and research papers derived from the composition of the tutoring module, the researchers integrated graphical programming into the module which resulted in a change to the graphic tutoring module. Therefore, the intelligent tutoring system could be summarized as

- Student module

- Graphical tutoring module

- Expert module

- Knowledge module

- Evaluation module

- User interface as shown in Fig 2

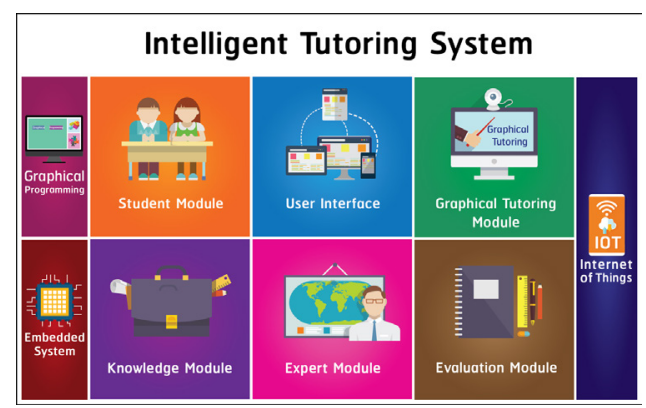

Fig. 2. Composition of an intelligent graphical tutoring system using the internet of things to develop efficiency in embedded systems. 
Paper-Analysis of an Intelligent Graphical Tutoring System using the Internet of Things (IoT)...

Table 2. Mean and standard deviations relating to the analysis of the composition of an intelligent graphical tutoring system using the internet of things to develop efficiency in embedded systems

\begin{tabular}{|c|c|c|c|}
\hline \multirow[t]{2}{*}{ Assessment Description } & \multicolumn{3}{|c|}{ Level of Proficiency } \\
\hline & $\bar{x}$ & S.D. & Result \\
\hline \multicolumn{4}{|c|}{ Composition of a graphical intelligent tutoring system } \\
\hline Graphical Tutoring Module & 4.80 & 0.45 & Very high \\
\hline Student Module & 4.20 & 0.45 & High \\
\hline Expert Module & 4.60 & 0.55 & Very high \\
\hline Knowledge Module & 4.20 & 0.45 & High \\
\hline Evaluation Module & 4.60 & 0.55 & Very high \\
\hline User Interface & 4.00 & 0.71 & High \\
\hline Mean & 4.40 & 0.52 & High \\
\hline
\end{tabular}

As illustrated in Table 2 the overall result was at a high level which indicates that the graphical tutoring module is the most suitable module for students since they can engage in the practice of graphical programming and gain a better understanding of its methods. This is followed by the expert module with an adaptive function for correcting responses to questions as well as being suitable for differing levels of student intelligence. Finally, the evaluation module includes a process of evaluation of students' learning and achievement and embedded system efficiency.

Table 3. Mean and standard deviation relating to the suitability of intelligent graphical tutoring system using the internet of things to develop the efficiency of embedded systems

\begin{tabular}{|l|l|l|l|}
\hline \multicolumn{1}{|c|}{ Assessment Descriptions } & \multicolumn{3}{c|}{ Level of Proficiency } \\
\cline { 2 - 4 } & \multicolumn{2}{c}{ Result } \\
\hline Suitability for adding the IoT context to course content & 4.80 & 0.45 & Very high \\
\hline Suitability for employing graphical programming as a tool & 4.40 & 0.45 & Very high \\
\hline Embedded system efficiency & 4.20 & 0.45 & High \\
\hline Suitability for practical application & 4.60 & 0.55 & Very high \\
\hline Mean & 4.50 & 0.50 & Very high \\
\hline
\end{tabular}

The data in Table 3 reveals that the overall result regarding the suitability of intelligent graphical tutoring system using the IoT to develop the efficiency of embedded systems is at a high level. It indicates that adding the IoT context to course content is the most suitable method conforming to the modern-day role that IoT plays in our connected lives and it leads to students learning new and appropriate skills. Secondly, employing graphical programming as a tool is found to be difficult for students to understand because it requires programs to be written in lines of code, whereas in graphical programming, students can create command blocks instead.

\section{Conclusion}

The synthesis of intelligent graphical tutoring system using the IoT to develop efficiency in embedded systems is summarized as follows: 
- The student module stores student information including their primary data, learning ability, learning effectiveness, learning improvement, study record and testing record etc.

- The user interface is an intelligent tutoring system used for interacting with users who can be teachers or learners by presenting educational media, learning activities, testing results, learning and teaching assessment results. The interface has elements that are easy to access and convenient navigation.

- The graphical tutoring module is a learning and management environment which uses graphical programming to allow students to create graphical programs without lines of code.

- The knowledge module is a data store for the body of knowledge containing articles that provide learners with questions and task resolutions to suit their individual needs. This module allows the sharing of educational materials and exams stored in the database.

- The expert module is an innovative teaching approach that uses teaching strategies adjusted to individual students' needs involving real world teaching and learning processes. It is also a central processing unit that supplements the intelligent tutoring system and assesses learners on completion of given topics, and then provides customized instructions to suit their needs.

- The evaluation module is an integral part of the learning achievement process and assessment of the efficiency of the embedded system.

The graphical programming program is employed as a tool for microcontrollers or for embedded system programming and enables the support of the IoT devices so that students can create innovative ideas and develop embedded system efficiency.

\section{Acknowledgement}

The researchers would like to thank the Faculty of Industrial Technology, Muban Chombueng Rajabhat University, Division of Information and Communication Technology for Education, Faculty of Technical Education, Vocational Education Technology Research Centre, Innovation and Technology Management Research Centre at the Science and Technology Research Institute and the King Mongkut's University of Technology North Bangkok, who all supported this research.

\section{$7 \quad$ References}

[1] T. Somsak and N. Prachyanun, "The Learning Process of Scientific Imagineering through AR in Order to Enhance STEM Literacy,” Int. J. Emerg. Technol. Learn., vol. 11, no. 7, pp. 57-63, 2016. https://doi.org/10.3991/ijet.v11i07.5357

[2] P. Nilsook and P. Wannapiroon, "International distance consulting via web conferencing," Int. J. Emerg. Technol. Learn., vol. 9, no. 4, pp. 60-64, 2014. https://doi.org/ $\underline{10.3991 / i j e t . v 9 i 4.3736}$ 
Paper-Analysis of an Intelligent Graphical Tutoring System using the Internet of Things (IoT)...

[3] M. Naghizadeh and H. Moradi, "A model for motivation assessment in intelligent tutoring systems,” 2015 7th Conf. Inf. Knowl. Technol. IKT 2015, 2015. https://doi.org/10 $.1109 /$ IKT.2015.7288774

[4] D. Wang, H. Han, Z. Zhan, J. Xu, Q. Liu, and G. Ren, "A problem solving oriented intelligent tutoring system to improve students' acquisition of basic computer skills," Comput. Educ., vol. 81, pp. 102-112, 2015. /10.1016/i.compedu.2014.10.003

[5] H. Victorio-Meza, M. Mejia-Lavalle, and G. R. Ortiz, "Advances on Knowledge Representation of Intelligent Tutoring Systems," 2014 Int. Conf. Mechatronics, Electron. Automot. Eng., pp. 212-216, 2014. https://doi.org/10.1109/ICMEAE.2014.17

[6] J. Marciniak, "Building intelligent tutoring systems immersed in repositories of e-learning content," Procedia Comput. Sci., vol. 35, no. C, pp. 541-550, 2014. https://doi.org/10.1 016/j.procs.2014.08.135

[7] V. M. Ramesh, N. J. Rao, and C. Ramanathan, "Implementation of an Intelligent Tutoring System using Moodle,” Proc. - Front. Educ. Conf. FIE, vol. 2014, 2015. https://doi.org/10. $\underline{1109 / F I E .2015 .7344313}$

[8] C.-K. Chang, "Effects of Using Alice and Scratch in an Introductory Programming Course for Corrective Instruction,” J. Educ. Comput. Res., vol. 51, no. 2, pp. 185-204, 2014. https://doi.org/10.2190/EC.51.2.c

[9] S. Techakosit and P. Nilsook, "The development of STEM literacy using the learning process of scientific imagineering through AR," Int. J. Emerg. Technol. Learn., vol. 13, no. 1, pp. 230-238, 2018. https://doi.org/10.3991/ijet.v13i01.7664

[10] W. Zhai, "Application of Data Mining Technology Based on Wireless Sensor Networks in Oceanographic Forecasting," vol. 14, no. 4, pp. 137-148, 2018.

[11] M. Jassas, J. Mathew, A. Azim, and Q. H. Mahmoud, "A framework for extending resources of embedded systems using the Cloud," Can. Conf. Electr. Comput. Eng., 2017.

[12] T. Laukkarinen, J. Suhonen, and M. Hännikäinen, "An embedded cloud design for internet-of-things," Int. J. Distrib. Sens. Networks, vol. 2013, 2013.

[13] J. S. He, D. C. Lo, Y. Xie, and J. Lartigue, "Integrating Internet of Things ( IoT ) into STEM Undergraduate Education: Case Study of a Modern Technology Infused Courseware for Embedded System Course," 2016.

[14] T. Murray, "An Overview of Intelligent Tutoring System Authoring Tools: Updated analysis of the state of the art," Authoring Tools Adv. Technol. Learn. Environ., pp. 493546, 2003.

[15] K. vanLehn, "The relative effectiveness of human tutoring, intelligent tutoring systems, and other tutoring systems," Educ. Psychol., vol. 46, no. 4, pp. 197-221, 2011. https://doi.org/10.1080/00461520.2011.611369

[16] M. Erdemir, Ş. İ. Kandil, and A. Karac1, "Student View on Web-Based Intelligent Tutoring Systems About Success and Retention of Physics Education,” Int. J. Manag. Public Sect. Inf. Commun. Technol., vol. 7, no. 2, pp. 3-10, 2016. https://doi.org/10.5 121/ijmpict.2016.7201

[17] Y. Zhang and Z. Liu, "A model of Web oriented intelligent tutoring system for distance education," Proc. - 5th Int. Conf. Comput. Intell. Multimed. Appl. ICCIMA 2003, pp. 7883, 2003. https://doi.org/10.1109/ICCIMA.2003.1238104

[18] M. F. Caro and J. A. Jiménez, "MOF-based metamodel for pedagogical strategy modeling in Intelligent Tutoring Systems," 2014 9th Comput. Colomb. Conf. 9CCC 2014, pp. 1-6, 2014. https://doi.org/10.1109/ColumbianCC.2014.6955365

[19] H. Gamboa and A. Fred, "Designing intelligent tutoring systems: a bayesian approach," Enterp. Inf. Syst. III, no. Fred 1994, p. 146, 2002. 
[20] D. Baneres and J. Saiz, "Intelligent Tutoring System for Learning Digital Systems on MOOC Environments," Proc. - 2016 10th Int. Conf. Complex, Intelligent, Softw. Intensive Syst. CISIS 2016, pp. 95-102, 2016. https://doi.org/10.1109/CISIS.2016.47

[21] S. Jimenez, R. Juarez-Ramirez, R. Navarro, A. Coronel, and V. H. Castillo, "Architecting an intelligent tutoring system with an affective dialogue module," Proc. - 2016 4th Int. Conf. Softw. Eng. Res. Innov. CONISOFT 2016, pp. 122-129, 2016.

[22] C. Conati, "Intelligent tutoring systems: new challenges and directions," Proc. 21st Int. jont Conf. Artifical Intell., vol. 9, pp. 2-7, 2009.

[23] K. K. R. Koedinger and A. Corbett, "Cognitive Tutors: Technology Bringing Learning Sciences to the Classroom," Cambridge Handb. Learn. Sci., no. January 2006, pp. 135168, 2006.

[24] P. P. Ray, “A Survey on Visual Programming Languages in,” Hindawi Sci. Program., vol. 2017, pp. 1-6, 2017.

[25] C. Xiajian, W. Danli, and W. Hongan, "Design and implementation of a graphical programming tool for children," Proc. - 2011 IEEE Int. Conf. Comput. Sci. Autom. Eng. CSAE 2011, vol. 4, pp. 572-576, 2011. https://doi.org/10.1109/CSAE.2011.5952915

[26] H. C. Lin, "An internet-based graphical programming tool for teaching power system harmonic measurement," IEEE Trans. Educ., vol. 49, no. 3, pp. 404-414, 2006. https://doi.org/10.1109/TE.2006.879239

[27] E. Lunca, S. Ursache, and O. Neacsu, "Graphical programming tools for electrical engineering higher education,” Int. J. Online Eng., vol. 7, no. 1, pp. 19-24, 2011. https://doi.org/10.3991/ijoe.v7i1.1403

[28] P. Fan and G. Zhou, "Analysis of the business model innovation of the technology of internet of things in postal logistics," 2011 IEEE 18th Int. Conf. Ind. Eng. Eng. Manag., pp. 532-536, 2011. https://doi.org/10.1109/ICIEEM.2011.6035215

[29] M. Ghazal, F. Haneefa, S. Ali, Y. Al Khalil, and A. Sweleh, "A Framework for Teaching Robotic Control Using a Novel Visual Programming Language,” no. October, pp. 16-19, 2016. https://doi.org/10.1109/MWSCAS.2016.7870095

[30] X. Xingmei, Z. Jing, and W. He, "Research on the basic characteristics, the key technologies, the network architecture and security problems of the Internet of things," Proc. 2013 3rd Int. Conf. Comput. Sci. Netw. Technol., pp. 825-828, 2013. https://doi.org/10.1 $\underline{\text { 109/ICCSNT.2013.6967233 }}$

[31] J. Chin and V. Callaghan, "Educational living labs: A novel internet-of-things based approach to teaching and research," Proc. - 9th Int. Conf. Intell. Environ. IE 2013, pp. 92 99, 2013. https://doi.org/10.1109/IE.2013.48

[32] M. Kranz, P. Holleis, and A. Schmidt, "Embedded interaction: Interacting with the internet of things," IEEE Internet Comput., vol. 14, no. 2, pp. 46-53, 2010. https://doi.org/10.1109/MIC.2009.141

[33] A. W. Burange and H. D. Misalkar, "Review of Internet of Things in development of smart cities with data management \& privacy," Conf. Proceeding - 2015 Int. Conf. Adv. Comput. Eng. Appl. ICACEA 2015, pp. 189-195, 2015. https://doi.org/10.110 9/ICACEA.2015.7164693

[34] A. Al-Fuqaha, M. Guizani, M. M.- S. \& Tutorials, and undefined 2015, "Internet of things: A survey on enabling technologies, protocols, and applications," Ieeexplore.Ieee.Org, vol. 17, no. 4, pp. 2347-2376, 2015.

[35] P. Peniak and M. Franekova, "Model of integration of embedded systems via CoAP protocol of Internet of Things," Int. Conf. Appl. Electron., vol. 2016-Septe, pp. 201-204, 2016. https://doi.org/10.1109/AE.2016.7577273 
[36] J. O. Hamblen and G. M. E. Van Bekkum, "An embedded systems laboratory to support rapid prototyping of robotics and the internet of things," IEEE Trans. Educ., vol. 56, no. 1, pp. 121-128, 2013. https://doi.org/10.1109/TE.2012.2227320

[37] R. Rollande and J. Grundspenkis, "Representation of study program as a part of graph based framework for tutoring module of intelligent tutoring system," 2012 2nd Int. Conf. Digit. Inf. Process. Commun. ICDIPC 2012, pp. 108-113, 2012. https://doi.org/10.11 09/ICDIPC.2012.6257276

[38] L. Kurup, A. Joshi, and N. Shekhokar, "Intelligent tutoring system for learning english punctuation,” Proc. - 2nd Int. Conf. Comput. Commun. Control Autom. ICCUBEA 2016, 2017.

[39] S. Abu Naser, a Ahmed, N. Al Masri, and Y. Abu Sultan, "Human Computer Interaction Design of the LP-ITS: Linear Programming Intelligent Tutoring Systems," Int. J. Artif. Intell. Appl., vol. 2, no. 3, pp. 60-70, 2011.

[40] S. S. Priya, R. Subhashini, and J. Akilandeswari, "Learning agent based knowledge management in Intelligent Tutoring System," 2012 Int. Conf. Comput. Commun. Informatics, pp. 1-5, 2012. https://doi.org/10.1109/ICCCI.2012.6158828

[41] K. Crockett, A. Latham, D. Mclean, and J. O'Shea, "A fuzzy model for predicting learning styles using behavioral cues in an conversational intelligent tutoring system," IEEE Int. Conf. Fuzzy Syst., 2013. https://doi.org/10.1109/FUZZ-IEEE.2013.6622382

[42] D. Hooshyar, R. B. Ahmad, M. Fathi, M. Yousefi, and M. Hooshyar, "Flowchart-based Bayesian Intelligent Tutoring System for computer programming," 2015 Int. Conf. Smart Sensors Appl. ICSSA 2015, pp. 150-154, 2015. https://doi.org/10. 1109/ICSSA.2015.7322528

[43] T. Zhihong, W. Liu, L. Libing, and Y. Zeqing, "The Application of Ontology Model in Intelligent Tutoring System,” Proc. - Int. Conf. Comput. Sci. Softw. Eng. CSSE 2008, vol. 5, pp. 1176-1179, 2008.

[44] I. Jugo, B. Kova??i??, and V. Slavuj, "Using data mining for learning path recommendation and visualization in an intelligent tutoring system," 2014 37th Int. Conv. Inf. Commun. Technol. Electron. Microelectron. MIPRO 2014 - Proc., no. May, pp. 924 928, 2014.

[45] R. Rahul, A. Whitchurch, and M. Rao, "An open source graphical robot programming environment in introductory programming curriculum for undergraduates," Proc. 2014 IEEE Int. Conf. MOOCs, Innov. Technol. Educ. IEEE MITE 2014, pp. 96-100, 2015.

[46] J. Lee, M. Stanley, A. Spanias, and C. Tepedelenlioglu, "Integrating machine learning in embedded sensor systems for Internet-of-Things applications," 2016 IEEE Int. Symp. Signal Process. Inf. Technol. ISSPIT 2016, pp. 290-294, 2017.

[47] M. Y. Si Allal Zarouk and M. Khaldi, "Towards an Intelligent Tutoring System developing Metacognition: Cyclical model," 2015 10th Int. Conf. Intell. Syst. Theor. Appl. SITA 2015, 2015. https://doi.org/10.1109/SITA.2015.7358437

[48] N. Thai-Nghe and L. Schmidt-Thieme, "Multi-relational Factorization Models for Student Modeling in Intelligent Tutoring Systems," Proc. - 2015 IEEE Int. Conf. Knowl. Syst. Eng. KSE 2015, pp. 61-66, 2016.

[49] D. P. Vinchurkar and M. Sasikumar, "Intelligent tutoring system for voice conversion in English,” Proc. - IEEE 15th Int. Conf. Adv. Learn. Technol. Adv. Technol. Support. Open Access to Form. Informal Learn. ICALT 2015, pp. 314-316, 2015. https://doi.org/10 1109/ICALT.2015.147

[50] A. Ramírez-Noriega, R. Juárez-Ramírez, and Y. Martínez-Ramírez, "Evaluation module based on Bayesian networks to Intelligent Tutoring Systems,” Int. J. Inf. Manage., vol. 37, no. 1, pp. 1488-1498, 2017. https://doi.org/10.1016/j.ijinfomgt.2016.05.007 


\section{Authors}

Jiragorn Chalermdit is a $\mathrm{PhD}$ candidate in the Information and Communication Technology for Education, Faculty of Technical Education, King Mongkut's University of Technology North Bangkok (KMUTNB), Bangkok, Thailand. His research interests focus on intelligent tutoring systems, the internet of things, embedded systems and graphical programming.

Prachyanun Nilsook is an associate professor at the Division of Information and Communication Technology for Education, King Mongkut's University of Technology North Bangkok (KMUTNB), Thailand. He currently works in the field of ICT for education and Vocational Education Technology Research Centre. He is a member of Professional Societies in the Association for Educational Technology of Thailand (AETT).

Panita Wannapiroon is an associate professor at the Division of Information and Communication Technology for Education, and the Director of Innovation and Technology Management Research Centre (ITMRC), Science and Technology Research Institute (STRI), King Mongkut's University of Technology North Bangkok (KMUTNB), Thailand. Presently, she works in the field of ICT in education.

Article submitted 09 September 2018. Final acceptance 08 December 2018. Final version published as submitted by the authors. 